ISSN 2766-5879

\title{
Statistics on Epidural Analgesia Made on Admitted Patients for Normal Vaginal Delivery, Outcome Results and Benefits
}

Gynecology and Women's Health Care

Research Article

Kariman Ghazal $^{1,2^{*}}$, Shahrazad Moallem ${ }^{3}$, Marita Yaghi
${ }^{1}$ Department of Obstetrics and Gynecology, Al Zahraa
Hospital University Medical Center, Beirut, Lebanon
${ }^{2}$ Department of Obstetrics and Gynecology Lebanese
University

${ }^{3}$ Head of Department of Anesthesia, Najjar Hospital, Beirut

${ }^{4}$ School of Medicine, American University of Beirut, Beirut, Lebanon

${ }^{5}$ Head of Department of Obstetrics and Gynecology Lebanese University

${ }^{6}$ Head of Obstetrics and Gynecology Department, Al Zahraa

Hospital University Medical Center, Beirut, Lebanon
*Correspondence author

\section{Kariman Ghazal}

Department of Obstetrics and Gynecology

Al Zahraa Hospital and Lebanese University

Beirut

Lebanon

Submitted : 5 Apr 2021 ; Published : 20 Apr 2021

\begin{abstract}
Introduction: Childbirth can be extremely painful. Labor pain is multifactorial and very complex, as it is a combination of visceral pain and somatic pain, in addition to psychological factors. Thus, the provision of effective pain relief during labor is an important element for a positive maternal experience. Epidural anesthesia is the most frequently used method of pain control In normal vaginal delivery (NVD), labor epidurals provide effective analgesia for laboring parturient.
\end{abstract}

Objective: of the present study was to review the maternal and fetal risks associated with epidural analgesia for pain relief during labor, and to investigate whether the use of epidural analgesia during labor was a risk factor for AVD and CS delivery.

Methods: We performed a 1-year (2020) prospective cohort analysis of the patients presenting at four obstetricled maternity units part of major academic medical centers in Beirut, Lebanon from January 2020 until December 2020. All eligible patients were approached for the consenting process, and those who agreed to participate in the study were included in the analysis. Patients were stratified in two groups based on the type of pain control they opted for/received at the time of admission: epidural delivered anesthesia or intravenous infusion of pain medications.

Results: A 100 eligible women consented to take part in the study, between January 1st, 2020 and December 31st, 2020. Maternal and fetal survival at the 30-days mark was 100.0\% for both groups. Duration of labor was significantly $0.1 \mathrm{~h}$ shorter in the epidural group with a mean of $6.7 \pm 1.8 \mathrm{~h}$ as opposed to $6.8 \pm 2.6 \mathrm{~h}$ in the nonepidural group. Use of forceps and/or vacuum was significantly higher in the epidural group 9 (17.3\%) and 2 $(3.8 \%)$ as opposed to 1 (2.1\%) and $0(0.0 \%)$ in the epidural group. A higher rate of severe perineal tears (grade 3 or more) was observed in women who received epidural anesthesia.

Conclusion: Epidural anesthesia is a safe option for pain control during vaginal delivery, both for the mother and the infant no effect on the duration of labor, and thus does not increase the risk of maternal or fetal infection or conversion to CS is also safe for neonates and is not associated with increased short term neonatal morbidity such as admission to the NICU. Epidural anesthesia however remains a risk factor for AVD and thus the use of instruments Its role as for severe perineal lacerations remains unclear according to our data, as we did not account for confounding factors. This last point remains to be investigated in large population-based studies.

Keywords : Epidural analgesia, induction of labor, childbirth, Labor Pain, Spontaneous Labor 


\section{Introduction}

Childbirth can be extremely painful and labor pain ranks high on the pain rating scaling as compared to other life experiences [1]. The release of corticotropin, cortisol, norepinephrine, betaendorphins and epinephrine is triggered by the stress response of labor [2]. Labor pain is multifactorial and very complex, as it is a combination of visceral pain and somatic pain, in addition to psychological factors [3,4]. Thus, the provision of effective pain relief during labor is an important element for a positive maternal experience.

Epidural anesthesia is the most frequently used method of pain control [5]. In normal vaginal delivery (NVD), labor epidurals are popular and safe; they provide effective analgesia for laboring parturient. Labor pain is mediated by T10 to L1 spinal segments in the first stage is mediated, then by T12 to L1, and $\mathrm{S} 2$ to S4 spinal segments in the second stage [3]. An epidural will deliver anesthesia into the epidural space of the spine, numbing the nerves and stopping pain signals from reaching the brain. During labor, epidural anesthesia is administered at lower doses, leading to efficient pain control while limiting motor blockade. If assisted, the laboring woman might still be able to get up and walk around [6]. Epidural anesthesia does not affect progress of labor and has minimal side effects to both the mother and the fetus. Labor epidurals can also be used to provide anesthesia for assisted vaginal delivery (AVD) or caesarean section (CS), and make the conversion from a NVD very fast and effective [7]. Typically, the dose of anesthesia provided is increased to provide stronger nerve blockade, including motor nerves. As compared to general anesthesia for CS, epidural anesthesia offers the advantage of keeping the mother awake and aware, thus not delaying the time the mother will meet her child.

Despite being safe, epidurals are not risk free. Some absolute contraindications to epidural anesthesia during labor are allergy to anesthetic agents or blood clotting problems [6]. Additionally, some of the risks of epidural is a quick drop in blood pressure or symptoms of nausea in the laboring woman.

Despite some side effects, epidurals have no effect on the progression of labor or method of delivery. However, a considerable number of obstetricians have the perception that epidurals slow down labor and are associated with higher rates of AVD or CS delivery [8].

The objective of the present study was to review the maternal and fetal risks associated with epidural analgesia for pain relief during labor, and to investigate whether the use of epidural analgesia during labor was a risk factor for AVD and CS delivery.

\section{Patients and Methods}

\section{Study Design and Population}

We performed a 1-year (2020) prospective cohort analysis of the patients presenting at four obstetric-led maternity units Al Zahraa Hospital, Makassed, Rafik Hariri University
Hospital Najjar part of major academic medical centers in Beirut, Lebanon from January 2020 until December 2020. The Hospital Al Zahraa Hospital University Medical Center Institutional Review Board granted this study from exemption. All eligible patients were approached for the consenting process, and those who agreed to participate in the study were included in the analysis.

\section{Inclusion and Exclusion Criteria}

We identified all adult (age, $\geq 18$ ) women presenting in labor presenting to the labor and delivery unit. Eligible women were those presenting at term ( $\geq 37$ weeks of gestation), with uncomplicated singleton pregnancies, a cephalic fetal presentation, and intending vaginal birth.

We excluded patients presenting in active spontaneous preterm labor, with twin gestation, or patients induced for maternal or fetal distress (premature rupture of membrane, chorioamnionitis, pre-eclampsia, eclampsia, intrauterine fetal demise, known fetal anomaly or known placental insufficiency). We also excluded patients with absolute indications for Caesarean section (fetal mal-presentation, placental abruption, abnormal placentation, uterine rupture, previous classic caesarean delivery, active HIV infection, and genital herpes)

\section{Procedure}

Patients received either an epidural regimen of anesthesia or intravenous (IV) analgesia, based on personal preference. $10 \mathrm{~mL} 0.5 \%$ Bupivacaine $+2 \mu \mathrm{g} / \mathrm{mL}$ of Fentanyl was administered to all women who opted for an epidural, through a patient-controlled epidural anesthesia (PCEA), with a 10-15 min lockout. Conversely, IV Meperidine at a rate of 20-35 mg per hour was administered to all women who opted against an epidural.

\section{Patient stratification}

Patients were stratified in two groups based on the type of pain control they opted for/received at the time of admission: epidural delivered anesthesia or intravenous infusion of pain medications.

\section{Outcomes}

Our primary outcome was measurement of the duration of labor. Our secondary outcomes included the rate of assisted vaginal deliveries and the methods used, the rate of caesarean sections performed, rate of perineal lacerations and neonatal admission to the Neonatal Intensive Care Unit (NICU).

\section{Data Points}

For each patient, we analyzed the following data points: demographics (age, educational level, occupation, type of area inhabited, nationality), body mass index, classification as advanced maternal age, obstetrical history, and obstetrical presentation (cervical dilation and cervical effacement).

\section{Statistical analysis}

To describe the baseline characteristics of the two patient groups, 
we performed descriptive statistics. Continuous parametric data were summarized using a mean and standard deviation, whereas continuous nonparametric data were summarized using a median and interquartile ranges. Categorical variables were summarized using counts and proportions. Comparison between the baseline characteristics and the outcomes between the study groups was performed using the independent t-test for continuous parametric data and the Manne Whitney U-test to compare continuous nonparametric data. Pearson's chisquare test was used to compare categorical variables.

We considered a $\mathrm{P}$ value of less than $0.05(\mathrm{P}<0.05)$ as statistically significant. All statistical analyses were carried out using the Statistical Package for the Social Sciences (SPSS, version 26; SPSS, Inc, Armonk, NY)

\section{Results}

\section{Patient characteristics}

A 100 eligible women consented to take part in the study, between January $1^{\text {st }}, 2020$ and December $31^{\text {st }}, 2020$.

Mean ( \pm SD) maternal age at delivery was $26.4 \pm 3.4$ in the epidural group, versus $26.5 \pm 4.9$ in the non-epidural group. Most women belonged to the normal BMI category, with 33 $(63.5 \%)$ of women in the epidural group and $31(64.6 \%)$ of women in the non-epidural group having a BMI of $18-24.9$. $50(96.1 \%)$ of women in the epidural group and $44(91.7 \%)$ in the non-epidural group lived in an urban area, and around half of them had a university degree, with $24(51.9 \%)$ in the epidural group and $25(52.1 \%)$ in the non-epidural group (Table 1).

\begin{tabular}{|c|c|c|c|}
\hline & & $\begin{array}{l}\text { Epidural } \\
\mathrm{N}=52\end{array}$ & $\begin{array}{l}\text { IV analgesia } \\
\mathrm{N}=48\end{array}$ \\
\hline \multicolumn{4}{|l|}{ Demographics } \\
\hline \multicolumn{2}{|c|}{ Age Mean \pm SD } & $26.4 \pm 3.4$ & $26.5 \pm 4.9$ \\
\hline \multirow{3}{*}{$\begin{array}{l}B \quad M \quad I \\
\text { category } \\
N(\%)\end{array}$} & $18.0-24.9$ & $33(63.5 \%)$ & $31(64.6 \%)$ \\
\hline & $25.0-29.9$ & $13(25.0 \%)$ & $11(22.9 \%)$ \\
\hline & $\geq 30.0$ & $6(11.5 \%)$ & $6(12.5 \%)$ \\
\hline \multirow{2}{*}{$\begin{array}{l}\text { Place } \\
\text { living } \\
\mathrm{N}(\%)\end{array}$} & Urban & $50(96.1 \%)$ & $44(91.7 \%)$ \\
\hline & Rural & $2(3.9 \%)$ & $4(8.3 \%)$ \\
\hline \multirow{3}{*}{$\begin{array}{l}\text { Education } \\
\mathrm{N}(\%)\end{array}$} & University & $24(51.9 \%)$ & $25(52.1 \%)$ \\
\hline & High school & $24(46.2 \%)$ & $19(39.6 \%)$ \\
\hline & $\begin{array}{l}\text { Elementary } \\
\text { school }\end{array}$ & $1(1.9 \%)$ & $1(2.1 \%)$ \\
\hline \multirow{3}{*}{$\begin{array}{l}\text { Nationality } \\
\text { N (\%) }\end{array}$} & Lebanese & $50(96.1 \%)$ & $36(75.0 \%)$ \\
\hline & Syrian & $2(3.9 \%)$ & $11(22.9 \%)$ \\
\hline & Palestinian & 0 & $1(2.1 \%)$ \\
\hline \multicolumn{4}{|c|}{ Presentation to labor } \\
\hline \multicolumn{2}{|c|}{$\begin{array}{l}\text { Cervical dilation, in } \mathrm{cm} \\
\text { Mean } \pm \mathrm{SD}\end{array}$} & $2.9 \pm 1.1$ & $3.5 \pm 1.6$ \\
\hline \multicolumn{2}{|c|}{$\begin{array}{l}\text { Cervical effacement, in } \% \\
\text { Mean } \pm \mathrm{SD}\end{array}$} & $58.3 \pm 9.8$ & $56.3 \pm 15.2$ \\
\hline
\end{tabular}

\begin{tabular}{|c|c|c|c|}
\hline \multicolumn{2}{|c|}{ Spontaneous labor N (\%) } & $22(42.3 \%)$ & $13(27.1 \%)$ \\
\hline \multicolumn{2}{|c|}{ Induction at term N (\%) } & $30(57.7 \%)$ & $35(72.9 \%)$ \\
\hline \multicolumn{4}{|c|}{ Obstetric history } \\
\hline \multicolumn{2}{|c|}{ Nulliparous N (\%) } & $40(76.9 \%)$ & $33(68.8 \%)$ \\
\hline \multicolumn{2}{|c|}{$\begin{array}{l}\text { Advanced maternal age } \mathrm{N} \\
(\%)\end{array}$} & $3(5.8 \%)$ & $5(10.4 \%)$ \\
\hline \multirow{3}{*}{$\begin{array}{l}\text { Gravida } \\
\mathrm{N}(\%)\end{array}$} & 1 & $35(67.3 \%)$ & $31(63.5 \%)$ \\
\hline & 2 & $8(15.4 \%)$ & $3(6.3 \%)$ \\
\hline & $>2$ & $9(17.3 \%)$ & $14(29.2 \%)$ \\
\hline \multirow{4}{*}{$\begin{array}{l}\text { Para } \\
\mathrm{N}(\%)\end{array}$} & 0 & $40(76.9 \%)$ & $33(63.5 \%)$ \\
\hline & 1 & $4(7.7 \%)$ & $2(3.8 \%)$ \\
\hline & 2 & $4(7.7 \%)$ & $6(11.5 \%)$ \\
\hline & $>2$ & $4(7.7 \%)$ & $7(13.5 \%)$ \\
\hline \multirow{3}{*}{$\begin{array}{l}\text { Aborta } \\
\mathrm{N}(\%)\end{array}$} & 0 & $43(82.7 \%)$ & $41(85.4 \%)$ \\
\hline & 1 & $8(15.4 \%)$ & $6(12.5 \%)$ \\
\hline & $>1$ & $1(1.9 \%)$ & $1(2.1 \%)$ \\
\hline
\end{tabular}

$3(5.8 \%)$ of women were classified in the advanced maternal age category in the epidural group vs. $5(10.4 \%)$ in the nonepidural group. $35(67.3 \%)$ of women in the epidural group were primigravid vs. $31(63.5 \%)$ in the non-epidural group (Table 1).

$22(42.3 \%)$ and $13(27.1 \%)$ of women presented to the labor and delivery unit in active spontaneous labor, respectively in the epidural and nonepidural group versus 30 (57.7\%) and 35 $(72.9 \%)$ who were induced at term in both groups respectively. Mean $( \pm \mathrm{SD})$ cervical dilation was $(2.9 \pm 1.1) \mathrm{cm}$ with a mean $( \pm \mathrm{SD})$ cervical effacement of $(58.3 \pm 9.8) \%$ in the epidural group. In the non-epidural group, mean $( \pm \mathrm{SD})$ cervical dilation and cervical effacement were of $(3.5 \pm 1.6) \mathrm{cm}$ and $(56.3 \pm$ 15.2) $\%$ respectively (Table 1 ).

\section{Labor and delivery outcomes}

Maternal and fetal survival at the 30-days mark was $100.0 \%$ for both groups. There were no reports of maternal fever, documented maternal infection, or maternal post-partum hemorrhage in both groups. None of the patients who received epidural anesthesia suffered from epidural site infection, central nervous system infection, epidural hematoma, neurological deficits including post-dural puncture headache or systemic anesthetic toxicity. None of the patients who did not receive epidural anesthesia suffered from complications related to intravenous infusion of analgesics, such as injection site infection, content extravasation or secondary systemic infection.

Duration of labor was significantly $0.1 \mathrm{~h}$ shorter in the epidural group with a mean of $6.7 \pm 1.8 \mathrm{~h}$ as opposed to $6.8 \pm 2.6 \mathrm{~h}$ in the non-epidural group. No significance difference was found between the women's presentation to the labor and delivery unit between both groups. The percentage of AVD was significantly higher in the epidural group, whereas the rate of CS was higher in the non-epidural group (Table 2). 


\begin{tabular}{|c|c|c|c|c|}
\hline & & Epidural $\mathrm{N}=52$ & IV analgesia $\mathrm{N}=48$ & Significance \\
\hline \multicolumn{5}{|l|}{ Labor Outcomes } \\
\hline \multicolumn{2}{|c|}{ Duration of labor in hours Mean \pm SD } & $6.7 \pm 1.8$ & $6.8 \pm 2.6$ & $* * p<0.01$ \\
\hline \multirow{2}{*}{ Presentation $N(\%)$} & Spontaneous term labor & $22(42.3 \%)$ & $13(27.1 \%)$ & \multirow{2}{*}{$p=0.11$} \\
\hline & Induction at term & $30(57.7 \%)$ & $35(72.9 \%)$ & \\
\hline \multirow[t]{3}{*}{ Delivery method $N(\%)$} & NVD & $6(11.5 \%)$ & $10(20.8 \%)$ & \multirow[t]{3}{*}{$* * p<0.01$} \\
\hline & AVD & $43(82.7 \%)$ & $21(43.8 \%)$ & \\
\hline & $\mathrm{CS}$ & $3(5.8 \%)$ & $17(35.4 \%)$ & \\
\hline \multirow{3}{*}{$\begin{array}{l}\text { Instrument use in } A V D \\
N(\%)\end{array}$} & Vacuum & $9(17.3 \%)$ & $1(2.1 \%)$ & \multirow[t]{3}{*}{$* * p<0.01$} \\
\hline & Forceps & $2(3.8 \%)$ & 0 & \\
\hline & Kristeller maneuver & $32(61.5 \%)$ & $20(40.7 \%)$ & \\
\hline \multirow{4}{*}{$\begin{array}{l}\text { Indications for } C S \\
N(\%)\end{array}$} & Failure of progression & $2(3.8 \%)$ & $8(16.7 \%)$ & \multirow[t]{4}{*}{$* * p<0.01$} \\
\hline & Failure of descent & 0 & $1(2.1 \%)$ & \\
\hline & Fetal distress & 0 & $3(6.3 \%)$ & \\
\hline & $\begin{array}{l}\text { Cephalopelvic } \\
\text { disproportion }\end{array}$ & $1(1.9 \%)$ & $5(10.4 \%)$ & \\
\hline \multicolumn{5}{|l|}{ Maternal Outcomes } \\
\hline Perineal tear N $(\%)$ & 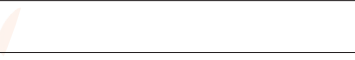 & $50(96.2 \%)$ & $30(62.5 \%)$ & $* * p<0.01$ \\
\hline \multirow{3}{*}{$\begin{array}{l}\text { Perineal tear grade } \\
\mathrm{N}(\%)\end{array}$} & $1^{\text {st }}$ grade & $28(23.1 \%)$ & $16(33.3 \%)$ & \multirow[t]{3}{*}{$* * p<0.01$} \\
\hline & $2^{\text {nd }}$ grade & $48(65.4 \%)$ & $14(29.2 \%)$ & \\
\hline & $3^{\text {rd }}$ grade & $4(7.7 \%)$ & 0 & \\
\hline \multicolumn{2}{|l|}{ Hypotension N (\%) } & $32(61.5 \%)$ & $11(22.9 \%)$ & $* * p<0.01$ \\
\hline \multicolumn{2}{|c|}{ Nausea and vomiting N (\%) } & $23(44.2 \%)$ & $2(4.2 \%)$ & $* * \mathrm{p}<0.01$ \\
\hline \multicolumn{5}{|l|}{ Neonatal Outcomes } \\
\hline \multicolumn{2}{|l|}{ Female baby N (\%) } & $19(36.5 \%)$ & $25(52.1 \%)$ & $p=0.12$ \\
\hline \multicolumn{2}{|c|}{ Baby weight in grams Mean \pm SD } & $3,258.7 \pm 296.2$ & $3,273.9 \pm 341.2$ & $p=0.08$ \\
\hline \multicolumn{2}{|c|}{ Meconium in liquor N (\%) } & $23(44.2 \%)$ & $18(37.5 \%)$ & $p=0.49$ \\
\hline \multirow[t]{2}{*}{ Meconium quantity } & Trace & $17(32.7 \%)$ & $10(20.8 \%)$ & \multirow[t]{2}{*}{$p=0.36$} \\
\hline & Moderate & $6(11.5 \%)$ & $8(16.7 \%)$ & \\
\hline \multicolumn{2}{|l|}{ NICU admission $\mathrm{N}(\%)$} & 0 & $13(27.1 \%)$ & $* * \mathrm{p}<0.01$ \\
\hline \multirow{2}{*}{$\begin{array}{l}\text { Reason for NICU } \\
\text { admission N (\%) }\end{array}$} & Respiratory distress & 0 & $7(14.6 \%)$ & $* * p<0.01$ \\
\hline & $\begin{array}{l}\text { Non-respiratory fetal } \\
\text { distress }\end{array}$ & 0 & $4(8.3 \%)$ & \\
\hline
\end{tabular}

Use of forceps and/or vacuum was significantly higher in the epidural group $9(17.3 \%)$ and $2(3.8 \%)$ as opposed to $1(2.1 \%)$ and $0(0.0 \%)$ in the epidural group. The use of the Kristeller maneuver was significantly lower in the epidural group with as opposed to the non-epidural group with 32 (61.5\%) and 20 (40.7\%) respectively. The indications for conversion to CS were also significantly different in both groups (Table 2).

$50(96.2 \%)$ of women in the epidural group developed a perineal tear versus $30(62.5 \%)$ in the non-epidural group. Perineal tears ranged from grade 1 to 3 in the epidural group while only grades 1 and 2 were observed in the non-epidural group. More women in the epidural group had a recorded episode of hypotension or nausea and vomiting, as compared to the women in the non-epidural group.

The presence of meconium in amniotic fluid was similar across both groups, as well as the quantity of meconium found. No infants from the group of mothers who received an epidural were admitted to the NICU versus $13(27.1 \%)$ infants in the non-epidural group. Respiratory distress occurred in 7 (14.6\%) infants and was the most common reason for NICU admission.

\section{Discussion}

We found that women who opted for epidural analgesia did not have a significantly greater maternal age or a higher BMI in comparison to women who opted for IV analgesia. Our findings were not consistent with those of large population studies in the United Kingdom, where advanced maternal age and a higher BMI were positively associated with the choice of epidural analgesia [9]. A more recent large population-based study in the United States demonstrated that distributions of age were similar between epidural users and nonusers [10]. On 
review of the literature, there are no studies directly reporting on the finding of increased rates of epidural analgesia in women with a higher BMI.

\section{Epidural risks and side effects}

The risk of complications post-epidural anesthesia was reported to be around $1.4 \%$ in recent studies, with epidural hematomas, post-operative neurologic deficits, post-dural puncture headache and systemic local anesthetic toxicity being the most common reported side effects [11]. None of these findings were reported in our study population. incidence in the epidural anesthesia group as compared to the non-epidural anesthesia group. This data is not consistent with previous findings [12].

\section{Effect on labor}

Our findings demonstrated labor to be significantly shorter rate of conversion to CS. Our findings show that women in the epidural group had significantly less risk of conversion to CS [13].

More women in the epidural group did however require an AVD, mainly with the use of forceps or vacuum. The higher rate of AVD in women receiving epidural anesthesia is consistent with previous data on epidural use $[13,14]$. Thus, epidural anesthesia presents a known risk factor for AVD.

A higher rate of severe perineal tears (grade 3 or more) was observed in women who received epidural anesthesia. In our analysis, we did not however control for the use of instruments to assist delivery as a confounding factor for severe perineal tears. Previous studies have reported findings similar to us, that were not significantly different once confounding factors were accounted for [15].

The main reason for conversion to $\mathrm{CS}$ in the non-epidural group of women was failure of progression, which only occurred in 1 woman who received epidural anesthesia.

\section{Neonatal outcomes}

Mean birth weight of infants was similar in both groups.

Our data shows that epidural anesthesia is safe for infants, as no infants of mothers who received an epidural were admitted to the NICU. Rate of NICU admission in the non-epidural group was significantly higher, with infants mainly developing respiratory distress. Our findings refute published literature about epidural anesthesia being a risk factor for neonatal respiratory distress and admission to the NICU [16]. Thus, epidural anesthesia has no effect on neonatal morbidity.

\section{Conclusion}

Epidural anesthesia is a safe option for pain control during vaginal delivery, both for the mother and the infant. It has no
Intrapartum nausea and vomiting had a significantly higher in the epidural group, however, this finding is not clinically significant. Our data refutes previous results that epidural analgesia prolongs the duration of labor, and thus, the increased

effect on the duration of labor, and thus does not increase the risk of maternal or fetal infection or conversion to CS. Epidural anesthesia is also safe for neonates and is not associated with increased short term neonatal morbidity such as admission to the NICU.

Epidural anesthesia however remains a risk factor for AVD and thus the use of instruments. Its role as an independent risk factor for severe perineal lacerations remains unclear according to our data, as we did not account for confounding factors. This last point remains to be investigated in large population-based studies.

\section{References}

1. Melzack R (1984) The myth of painless childbirth (the John J Bonica lecture). Pain 19: 321-337.

2. Hawkins JL (2010) Epidural analgesia for labor and delivery. New England Journal of Medicine 362: 1503 1510.

3. Labor S, Maguire S (2008) The pain of labour. Reviews in pain 2: 15-19.

4. Lundgren I, Dahlberg K (1998) Women's experience of pain during childbirth. Midwifery 14: 105-110.

5. Kukulu K, Demirok H(2008) Effects of epidural anesthesia on labor progress. Pain Management Nursing 9: 10-16.

6. Institute for Quality and Efficiency in Health Care (IQWiG). Pregnancy and birth: Epidurals and painkillers for labor pain relief. Informed Health Online. Germany 2006.

7. Kingsley CM (2019) Alan; Labour Epidural: The Basics. World Federation of Societies of Anesthesiologists. 2019 (Week 365).

8. Sohaib M, Ismail S (2015) Does labour epidural slow the progress of labour and lead to complications? Obstetricians' perception working in private and public sector teaching hospitals in a developing country. Indian journal of anaesthesia 59: 779.

9. Antonakou A, Papoutsis D (2016) The effect of epidural analgesia on the delivery outcome of induced labour: a retrospective case series. Obstetrics and gynecology international 2016.

10. Harkins J, Carvalho B, Evers A, Mehta S, Riley ET (2010) Survey of the factors associated with a woman's choice to have an epidural for labor analgesia. Anesthesiology research and practice 2010.

11. Kang XH, Bao FP, Xiong XX, Li M, Jin TT, et al. (2014) Major complications of epidural anesthesia: a prospective study of 5083 cases at a single hospital. Acta Anaesthesiologica Scandinavica 58: 858-866.

12. Wang F, Shen X, Guo X, Peng Y, Gu X, Group LAE (2009) Epidural analgesia in the latent phase of labor and the risk of cesarean delivery: a five-year randomized controlled trial. The Journal of the American Society of Anesthesiologists 111: 871-880.

13. Liu E, Sia A (2004) Rates of caesarean section and instrumental vaginal delivery in nulliparous women after low concentration epidural infusions or opioid analgesia: systematic review. Bmj 328: 1410. 
14. Anim-Somuah M, Smyth RM, Jones L (2011) Epidural versus non-epidural or no analgesia in labour. Cochrane database of systematic reviews 2011.

15. Loewenberg-Weisband Y, Grisaru-Granovsky S, Ioscovich A, Samueloff A, Calderon-Margalit R (2014) Epidural analgesia and severe perineal tears: a literature review and large cohort study. The Journal of Maternal-Fetal \& Neonatal Medicine 27: 1864-1869.

16. Salameh KM, Paraparambil VA, Sarfrazul A, Hussain HL, Thyvilayil SS, et al. (2020) Effects of labor epidural analgesia on short term neonatal morbidity. International journal of women's health 12: 59.

Copyright: ( 2021 Kariman Ghazal. This is an open-access article distributed under the terms of the Creative Commons Attribution License, which permits unrestricted use, distribution, and reproduction in anymedium, provided the original author and source are credited. 